\title{
Cancer-Associated Thrombosis
}

\author{
Mehran Karimi* and Nader Cohan
}

Hematology Research Center, Shiraz University of Medical Sciences, Shiraz, Iran

\begin{abstract}
Thrombosis is a common complication in patients with cancer and it is estimated that about $20 \%$ of patients with cancer experience venous thromboembolism (VTE). This complication is associated with high rate of morbidity and mortality and is sometimes the first manifestation of an occult cancer. The risk profiles and markers involved in cancerassociated thrombosis share similarities with inflammation-induced atherosclerosis and thrombosis. The type of cancer, chemotherapy, surgery, central venous catheters, pre-chemotherapy platelet and leukocyte count are associated with high risk of VTE in cancer patients. Landmark studies demonstrated that effective prophylaxis and treatment of VTE reduced morbidity and increased survival. Low-molecular-weight heparin (LMWH) is preferred as an effective and safe means for prophylaxis and treatment of VTE. It has largely replaced unfractionated heparin and vitamin K antagonists. The advantages of LMWH include increased survival and quality of life, decreased rate of VTE, low incidence of thrombocytopenia. New guidelines for prophylaxis and treatment are now available and prophylaxis is recommended in hospitalized cancer patients and patients undergoing major surgery. Treatment with LMWH should be considered as the first line of therapy for established VTE and to prevent recurrent thrombosis in patients with cancer.
\end{abstract}

Keywords: Cancer, Thrombosis, Low-molecular-weight heparin.

\section{INTRODUCTION}

Thrombosis, a well-recognized complication of cancer, may be the first manifestation of malignancy and is associated with a high rate of morbidity and mortality [1-4]. This association was first described by Armand Trousseau in 1865 and the condition still often called Trousseau's syndrome [5-7].

The clinical manifestations of thrombosis in cancer vary from venous thromboembolism (VTE) to disseminated intravascular coagulation, which is more commonly seen in hematological malignancies [8]. Venous thromboembolism in patients with cancer may present as a vast range of clinically significant thrombotic complications including deep vein thrombosis, pulmonary embolism, arterial thrombosis, nonbacterial thrombotic endocarditis, superficial thrombophlebitis, catheter-related thrombosis and hepatic venoocclusive disease [9-11].

Certain malignancies, particularly mucin-secreting adenocarcinomas of the ovary, pancreas, stomach, brain tumors and hematological malignancies, are associated with a higher risk of VTE [12-16]. Some conditions are well-known risk factors for increased risk of thrombosis in patients with cancer. Chemotherapy is one of the most important risk factors for increased risk of VTE [10-12]. The strongest clinical relationship between chemotherapy and thrombosis was found in patients with breast cancer receiving chemotherapy $[10,12-15]$. In a study by the Eastern Cooperative Oncology Group, VTE was significantly more common in patients with

*Address correspondence to this author at the Hematology Research Center, Nemazee Hospital of Shiraz University of Medical Sciences, Zand st, Shiraz, Iran; Tel/Fax: +98 711 6473239; E-mail: Karimim@sums.ac.ir breast cancer who underwent chemotherapy and hormonal therapy than in the control group [16]. A high incidence of VTE following chemotherapy was also reported in other cancers $[17,18]$. Chemotherapy increased the risk of VTE and recurrent VTE 6-fold and 2-fold, respectively in patients with cancer, and it is estimated that the annual incidence of VTE in cancer patients undergoing chemotherapy is about $10.9 \%$ [10].

Surgery is estimated to increase the risk of postoperative VTE about 2-fold in patients with cancer compared to patients without cancer who underwent surgery and was associated with a 3-fold to 4-fold increase in the likelihood of developing pulmonary embolism after surgery [19-21]. In contrast, some studies did not show an increased risk of VTE associated with surgery in patients with cancer $[14,22]$. One study that analyzed the effect of neurosurgery on the risk of thrombosis in patients with glioma revealed that these patients were $70 \%$ more likely to develope VTE compared to patients who did not undergo surgery [14]. Other risk factors for thrombosis in cancer are central venous catheters, immobilization, oral contraceptive use, trauma, previous vein thrombosis, hormonal therapy, pregnancy, older age, prothrombotic mutations such as factor $\mathrm{V}$ leiden and prothrombin 20210A, elevated D-dimer levels, elevated C-reactive protein, elevated soluble P-selectin, body mass index $\geq 35 \mathrm{~kg} / \mathrm{m}^{2}$, antiphospholipid antibody and several biomarkers such as pre-chemotherapy platelet count over $350 \times 10^{3} / \mu \mathrm{L}$ or leukocyte count over $11 \times 10^{3} / \mu \mathrm{L}[14,22$ 26].

Also it is noted that risk factors and markers involved in cancer-associated thrombosis, inflammation and atherosclerosis share similarities. Thrombogenic risk factors such as tissue factor reported as a promotion factor for a human 
coronary atherosclerosis plague. In addition, platelets can release pro-inflammatory substances relevant to atherothrombosis. Beside the cardiovascular risk factors including; family history of coronary heart disease, smoking, high cholesterol level, hypertension, age and diabetic mellitus several markers including fibrinogen level, markers of fibrinolytic systems and inflammation markers such as Creactive protein is evaluated as risk factors of cardiovascular disease [27, 28].

The aim of this review was to overview evidence on pathophysiology, prophylaxis and treatment of cancerassociated thrombosis.

\section{PATHOPHYSIOLOGY OF CANCER-ASSOCIATED THROMBOSIS}

The pathophysiology of thrombosis formation and blood coagulation in cancer is complex and reflects different mechanisms that are generally related to the host response to cancer. These mechanisms include activation of the coagulation and fibrinolytic systems, acute phase reaction, inflammation, necrosis and cytokine production [5, 8, 29, 30]. Malignant cells can directly activate blood coagulation by producing tissue factor, cancer procoagulant activity, inflammatory reactions and cytokines [9, 12, 29, 31].

Tissue factor, an important coagulation factor that has been reported in many types of cancers [32], is constitutively expressed on solid malignant cells and acute myelogenous leukemia cells. It has been reported to promote thrombotic state $[30,31,33]$.

Cancer procoagulant is a $68-\mathrm{kDa}$ cysteine endopeptidase that can directly activate coagulation factor X. It is released by many tumor cells and its activity promotes thrombosis. It is also has been shown that cancer procoagulant can cause platelet activation $[8,10,34,35]$.

Malignant cells release various types of cytokines including interleukin (IL)-1 $\beta$, tumor necrosis factor- $\alpha$ and vascular endothelial growth factor (VEGF), which have important effects on coagulation. These cytokines can induce tissue factor production by vascular endothelial cells, downregulate thrombomodulin expression, produce plasminogen activator inhibitor-1 and increase endothelial cell adhesion molecule expression. This last effect increases the capacity of the vessel wall to attach leukocytes and platelets, promoting localized clotting factor activation and thrombosis formation [8$10,29,36]$. Angiogenesis is an important process in pathophysiology of cancer. VEGF and angiopoietins with their receptors, Flt-1 for VEGF and Tie-2 for angiopoietin, that are the most potent proangiogenic factors are involved in the pathogenesis of cancer. Abnormal levels of VEGF, angiopoietins, IL-6 (an inflammatory cytokine) and soluble $\mathrm{P}$ selectin and their receptors are established in breast and other cancers that treatment is effective in reduce levels of these markers [37-39].

Interactions between malignant and endothelial host cells, platelets and leukocytes are another mechanism by which tumor cells promote thrombosis. The attachment of malignant cells can promote thrombosis by activating localized clotting factor, favoring platelet aggregation and activating leukocytes which then release their cytokines $[8,10,29$, 40].

It has also been shown that inflammation induced by cancer can increase acute-phase proteins including fibrinogen, coagulation factor VIII and von Willebrand factor, which can promote thrombosis [9, 41]. Fig. (1) illustrates

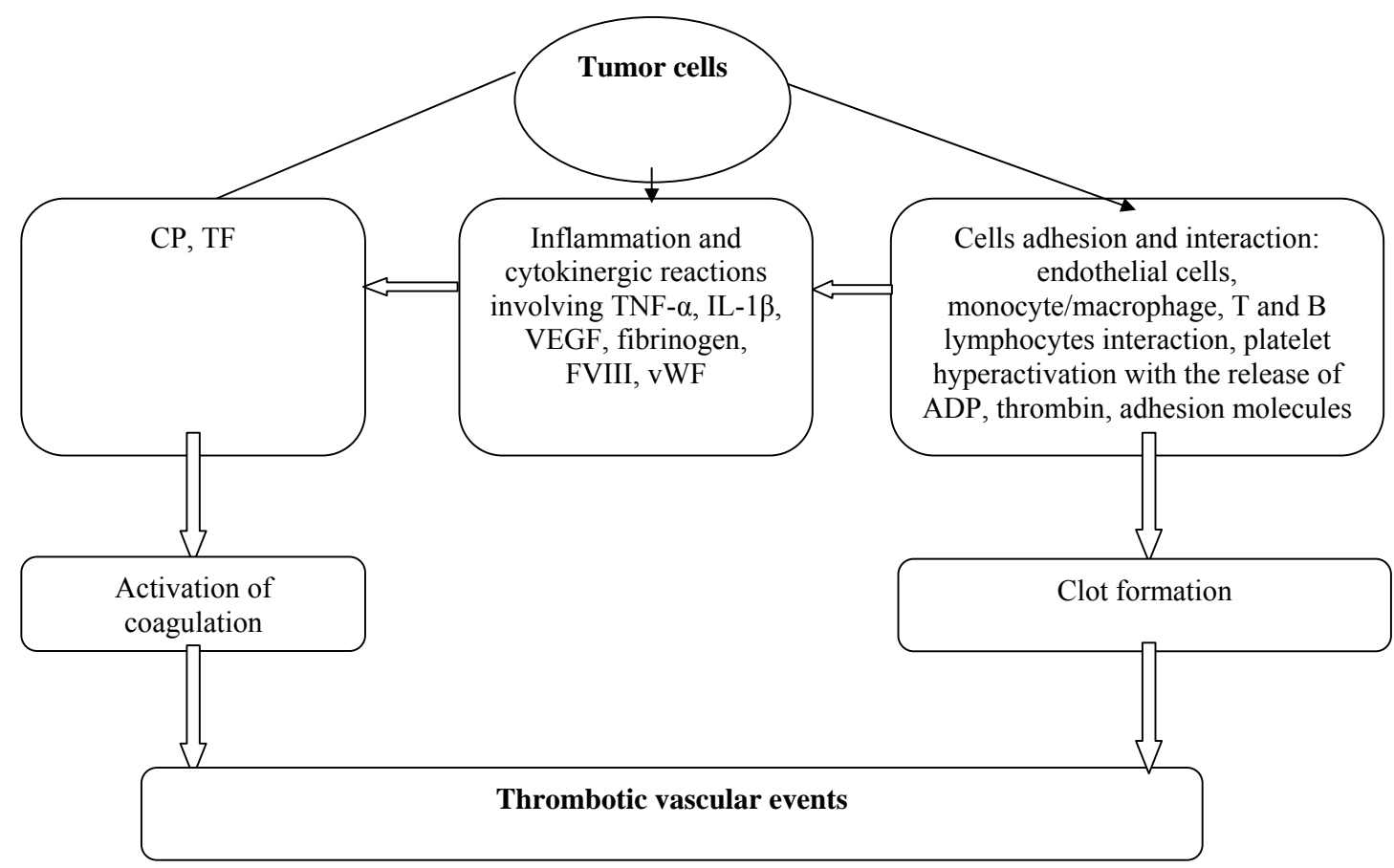

Fig. (1). Factors involved in cancer-associated thrombosis. 
the mechanism of thrombosis formation induced by cancer cells.

\section{EPIDEMIOLOGY \\ OF CANCER-ASSOCIATED THROMBOSIS}

It is estimated that about $4-20 \%$ of patients with cancer experience venous thrombosis $[7,10,25,30,42,43]$ with the annual incidence of $0.5 \%$ in cancer patients compared to $0.1 \%$ in the general population [25]. In patients with cancer, the risk of VTE is estimated to be 4-fold to 7-fold higher than in patients without cancer [44]. Venous thromboembolism and thrombotic complications are the second most frequent cause of mortality in patients with cancer [10].

Several studies have showed that the incidence of VTE is associated with the duration of the underlying illness. The highest rate of VTE is seen in the initial period after diagnosis $[14,29,45]$ and mortality from VTE is highest 1 year after diagnosis [14]. Alcalay et al. showed that the incidence of VTE in patients with colorectal cancer is about $5.0 \%$ during the first 6 months after diagnosis, $1.4 \%$ during the subsequent 7-12 months and 0.6\% 13-24 months after diagnosis [46]. The appearance of venous thrombosis has been clearly associated with metastatic cancer and the stage of cancer [14, $29,42,44]$. About $10 \%$ of patients with idiopathic thrombotic complications are diagnosed with malignancy within a few years after thrombotic events and approximately $40 \%$ of them have metastatic cancer at diagnosis [47, 48]. As a result VTE is sometimes the first manifestation of occult cancer $[10,29,42,47]$. In a study by Monreal et al. the rate of occult cancer in patients with idiopathic VTE was 2.2\%-12\% [48]. More advanced stages of cancer on initial diagnosis are also related with a higher incidence of VTE $[14,45,46]$.

The presence of medical comorbodity has an adverse effect on prognosis and survival in patients with cancer who also have thrombosis [47]. Khorana et al. proposed a simple risk scoring system based on clinical and laboratory variables to predict chemotherapy-associated VTE in patients with cancer [25,49]. They identified five variables based on the site of cancer, pre-chemotherapy platelet and leukocyte count, hemoglobin level and body mass index. This model predicts a risk of chemotherapy-associated VTE in of about $7 \%$ in patients with cancer [25].

\section{PREVENTION AND TREATMENT OF VENOUS THROMBOEMBOLISM IN CANCER}

Effective prophylaxis and treatment of VTE can reduce morbidity and mortality due to thrombosis. Low-molecularweight-heparin (LMWH) is the first choice for prophylaxis and treatment of acute VTE, having largely replaced unfractionated heparin and oral vitamin $\mathrm{K}$ antagonists such as warfarin [50,51].

Warfarin is a long-term anticoagulant for the prevention and treatment of VTE that is given after initial therapy with unfractionated heparin or LMWH to maintain an international normalized ratio of 2-3 [42, 52]. But warfarin treatment in patients with cancer has several problems that have limited its use. Long-term treatment with warfarin increases the risk of bleeding and recurrent VTE in patients with cancer $[47,53,54]$. Difficulties in dose adjustment also limit its use because the anticoagulant effect may reach to its peak after 3-4 days and its clearance from plasma is slow. Also warfarin may interact with chemotherapeutic agents and foods-interactions that also make this drug difficult to manage [12].

The CLOT trial (Comparison of Low-Molecular-Weight Heparin Versus Oral Anticoagulant Therapy for the Prevention of Recurrent Venous Thromboembolism in Patients with Cancer) compared the efficacy of LMWH plus dalteparin and oral warfarin in preventing recurrent VTE in patients with cancer. Recurrent VTE was found in 27 of 336 patients in the LMWH group compared to 53 of 336 patients in the warfarin group (hazard ratio 0.48, $\mathrm{P}=0.002$ ) [55]. Low-molecular-weight heparin and dalteparin reduced the risk of recurrent VTE by $52 \%$ compared to warfarin therapy [56].

Unfractionated heparin is also widely used for the treatment and prophylaxis of thrombophylactic events and its efficacy is similar to that of LMWH [56]. A metaanalysis revealed that unfractionated heparin decreased the incidence of deep vein thrombosis and pulmonary embolism by $56 \%$ and $58 \%$ respectively compared to the control group [57]. The most important limitation of unfractionated heparin is the appearance of heparin-induced thrombocytopenia, which is significantly less frequent with $\mathrm{LMWH}[9,29]$. Treatment with LMWH led to a significant proportion of improvements in thrombosis and higher survival compared to unfractionated heparin [9]. These benefits make subcutaneous (sc) LMWH the first-line choice for the treatment and prophylaxis of thrombosis in patients with cancer.

Randomized trials to test different types of prophylaxis for VTE in patients with cancer showed significantly lower rates of VTE with LMWH compared to unfractionated heparin or a placebo [58-60]. New treatment guidelines from the National Comprehensive Cancer Network (NCCN) and American Society of Clinical Oncology (ASCO) accept prophylaxis for VTE in hospitalized cancer patients in the absence of major bleeding or other contraindications to anticoagulants $[50,61]$. Contraindications to anticoagulation according to ASCO guidelines include uncontrollable bleeding, active cerebrovascular hemorrhage, dissecting or cerebral aneurysm, bacterial endocarditis, active peptic or other gastrointestinal ulceration, severe uncontrolled or malignant hypertension, severe head trauma, pregnancy (warfarin), heparin-induced thrombocytopenia and epidural catheter placement.

It is recommended that patients undergoing major surgery for cancer should be considered candidates for thrombophylaxis, although routine prophylaxis is not recommended in ambulatory cancer patients without VTE except in patients with myeloma receiving thalidomide or lenalidomide treatment [50]. Low-molecular-weight heparin, dalteparin 5000 units s.c daily, enoxaparin $40 \mathrm{mg}$ s.c daily or fondaparinux $2.5 \mathrm{mg}$ s.c daily is recommended for prophylaxis of VTE in patients with cancer [50,61,62]. A randomized clinical trial of combination chemotherapy with LMWH with dalteparin 5000 units once daily for 18 weeks compared to chemotherapy alone in patients with small-cell lung cancer revealed that combination therapy with dalteparin increased disease-free survival $(10$ months $)$ compared chemotherapy alone (6 months, $\mathrm{P}=0.01$ ) [63]. 


\section{CONCLUSIONS}

Venous thromboembolism is a serious complication and the second most frequent cause of death in patients with cancer. The appearance of VTE reduces survival in cancer patients compared to those without VTE and adversely affects quality of life [14]. It is estimated that thrombosis in patients with cancer increases the risk of death 4-fold to 8fold compared to patients without cancer [47]. Landmark studies showed that anticoagulant therapy and thromboprophylaxis are efficacious and can protect patients from VTE. Based on clinical trial findings, subcutaneous LMWH is the first line therapy for VTE in patients with cancer and has largely replaced unfractionated heparin and vitamin $\mathrm{K}$ antagonists. New treatment and prophylaxis guidelines are now available for the management of thrombotic events and these guidelines can decrease complications and morbidity and increase survival and quality of life in patients with cancer.

\section{ACKNOWLEDGEMENTS}

We thank Shirin Parand (Hematology Research Center, Shiraz University of Medical Sciences) and K. Shashok (AuthorAID in the Eastern Mediterranean) for improving the use of English in the manuscript.

$\begin{array}{lll}\text { ABBREVIATIONS } \\ \mathrm{CP} & =\text { Cancer procoagulant } \\ \mathrm{TF} & =\text { Tissue factor } \\ \mathrm{TNF}-\alpha & \text { Tumor necrosis factor- } \alpha \\ \mathrm{IL}-1 \beta & = & \text { Interleukin-1 } \beta \\ \mathrm{VEGF} & = & \text { Vascular endothelial growth factor } \\ \mathrm{FVIII} & = & \text { Factor VIII } \\ \mathrm{vWF} & = & \text { Von Willebrand factor } \\ \mathrm{ADP} & = & \text { Adenosine diphosphate }\end{array}$

\section{REFERENCES}

[1] Lee AY, Levine MN. Venous thromboembolism and cancer: risks and outcomes. Circulation 2003; 107: I17-21.

[2] White RH, Chew HK, Zhou H, et al. Incidence of venous thromboembolism in the year before the diagnosis of cancer in 528,693 adults. Arch Intern Med 2005; 165: 1782-7.

[3] Prandoni P, Piccioli A, Girolami A. Cancer and venous thromboembolism: an overview. Haematologica 1999; 84: 437-45.

[4] Caine GJ, Stonelake PS, Lip GY, Kehoe ST. The hypercoagulable state of malignancy: pathogenesis and current debate. Neoplasia 2002; 4: 465-73.

[5] Bick RL. Cancer-associated thrombosis. N Engl J Med 2003; 349: 109-11.

[6] Sato T, Tsujino I, Ikeda D, Ieko M, Nishimura M. Trousseau's syndrome associated with tissue factor produced by pulmonary adenocarcinoma. Thorax 2006; 61: 1009-10.

[7] Khorana AA, Francis CW, Culakova E, Kuderer NM, Lyman GH. Thromboembolism is a leading cause of death in cancer patients receiving outpatient chemotherapy. J Thromb Haemost 2007; 5: 6324.

[8] Rickles FR, Falanga A. Molecular basis for the relationship between thrombosis and cancer. Thromb Res 2001; 102: V215-24.

[9] Deitcher SR. Cancer and thrombosis: mechanisms and treatment. J Thromb Thrombolysis 2003; 16: 21-31.

[10] Haddad TC, Greeno EW. Chemotherapy-induced thrombosis. Thromb Res 2006; 118: 555-68.
[11] Gomes MP, Deitcher SR. Diagnosis of venous thromboembolic disease in cancer patients. Oncology (Williston Park) 2003; 17: 126-35.

[12] Falanga A, Zacharski L. Deep vein thrombosis in cancer: the scale of the problem and approaches to management. Ann Oncol 2005; 16: 696-701.

[13] Pritchard KI, Paterson AH, Paul NA, Zee B, Fine S, Pater J. Increased thromboembolic complications with concurrent tamoxifen and chemotherapy in a randomized trial of adjuvant therapy for women with breast cancer. National Cancer Institute of Canada Clinical Trials Group Breast Cancer Site Group. J Clin Oncol 1996; 14: 2731-7.

[14] Wun T, White RH. Venous thromboembolism (VTE) in patients with cancer: epidemiology and risk factors. Cancer Invest 2009; 27 (Suppl 1): 63-74.

[15] Blom JW, Doggen CJ, Osanto S, Rosendaal FR. Malignancies, prothrombotic mutations, and the risk of venous thrombosis. JAMA 2005; 293: 715-22.

[16] Saphner T, Tormey DC, Gray R. Venous and arterial thrombosis in patients who received adjuvant therapy for breast cancer. J Clin Oncol 1991; 9: 286-94.

[17] Hurwitz H, Fehrenbacher L, Novotny W, et al. Bevacizumab plus irinotecan, fluorouracil, and leucovorin for metastatic colorectal cancer. N Engl J Med 2004; 350: 2335-42.

[18] Rubbia-Brandt L, Audard V, Sartoretti P, et al. Severe hepatic sinusoidal obstruction associated with oxaliplatin-based chemotherapy in patients with metastatic colorectal cancer. Ann Oncol 2004; 15: 460-6.

[19] Donati MB. Cancer and thrombosis. Haemostasis 1994; 24: 12831.

[20] Prandoni P. Antithrombotic strategies in patients with cancer. Thromb Haemost 1997; 78: 141-4.

[21] Levitan N, Dowlati A, Remick SC, et al. Rates of initial and recurrent thromboembolic disease among patients with malignancy versus those without malignancy. Risk analysis using Medicare claims data. Medicine (Baltimore) 1999; 78: 285-91.

[22] Heit JA, Silverstein MD, Mohr DN, Petterson TM, O'Fallon WM, Melton LJ 3rd. Risk factors for deep vein thrombosis and pulmonary embolism: a population-based case-control study. Arch Intern Med 2000; 160: 809-15.

[23] Goldhaber SZ, Tapson VF; DVT FREE Steering Committee. A prospective registry of 5,451 patients with ultrasound-confirmed deep vein thrombosis. Am J Cardiol 2004; 93: 259-62.

[24] Chasan-Taber L, Stampfer MJ. Epidemiology of oral contraceptives and cardiovascular disease. Ann Intern Med 1998; 128: 46777.

[25] Sud R, Khorana AA. Cancer-associated thrombosis: risk factors, candidate biomarkers and a risk model. Thromb Res 2009; 123 (Suppl 4): S18-21.

[26] Horowitz N, Brenner B. Thrombophilia and cancer. Pathophysiol Haemost Thromb 2008; 36: 131-6.

[27] Packard RR, Libby P. Inflammation in atherosclerosis: from vascular biology to biomarker discovery and risk prediction. Clin Chem 2008; 54: 24-38.

[28] Libby P, Ridker PM, Maseri A. Inflammation and atherosclerosis. Circulation 2002; 105: 1135-43.

[29] Prandoni P, Falanga A, Piccioli A. Cancer, thrombosis and heparininduced thrombocytopenia. Thromb Res 2007; 120 (Suppl 2): S137-40.

[30] López JA, Chen J. Pathophysiology of venous thrombosis. Thromb Res 2009; 123 (Suppl 4): S30-4.

[31] Falanga A, Donati MB. Pathogenesis of thrombosis in patients with malignancy. Int J Hematol 2001; 73: 137-44.

[32] Zwicker JI. Tissue factor-bearing microparticles and cancer. Semin Thromb Hemost 2008; 34: 195-8.

[33] Davila M, Amirkhosravi A, Coll E, et al. Tissue factor-bearing microparticles derived from tumor cells: impact on coagulation activation. J Thromb Haemost 2008; 6: 1517-24.

[34] Lee AY. Cancer and thromboembolic disease: pathogenic mechanisms. Cancer Treat Rev 2002; 28: 137-40.

[35] Rickles FR, Hair GA, Zeff RA, Lee E, Bona RD. Tissue factor expression in human leukocytes and tumor cells. Thromb Haemost 1995; 74: 391-5.

[36] Grignani G, Maiolo A. Cytokines and hemostasis. Haematologica 2000; 85: 967-72. 
[37] Caine GJ, Lip GY, Zanetto U, Maheshwari M, Stonelake PS, Blann AD. A comparison of plasma versus histologic indices of angiogenic markers in breast cancer. Appl Immunohistochem Mol Morphol 2007; 15: 382-8.

[38] Caine GJ, Stonelake PS, Lip GY, Blann AD. Changes in plasma vascular endothelial growth factor, angiopoietins, and their receptors following surgery for breast cancer. Cancer Lett 2007; 248: 131-6.

[39] Caine GJ, Lip GY, Blann AD. Platelet-derived VEGF, Flt-1, angiopoietin-1 and P-selectin in breast and prostate cancer: further evidence for a role of platelets in tumour angiogenesis. Ann Med 2004; 36: 273-7.

[40] Lo SK, Cheung A, Zheng Q, Silverstein RL. Induction of tissue factor on monocytes by adhesion to endothelial cells. J Immunol 1995; 154: 4768-77.

[41] Deitcher SR, Carman TL, Sheikh MA, Gomes M. Hypercoagulable syndromes: evaluation and management strategies for acute limb ischemia. Semin Vasc Surg 2001; 14: 74-85.

[42] Dotsenko O, Kakkar AK. Thrombosis and cancer. Ann Oncol 2006; 17 (Suppl 10): x81-4.

[43] Heit JA, O'Fallon WM, Petterson TM, et al. Relative impact of risk factors for deep vein thrombosis and pulmonary embolism: a population-based study. Arch Intern Med 2002; 162: 1245-8.

[44] Stein PD, Beemath A, Meyers FA, Skaf E, Sanchez J, Olson RE. Incidence of venous thromboembolism in patients hospitalized with cancer. Am J Med 2006; 119: 60-8.

[45] Chew HK, Wun T, Harvey DJ, Zhou H, White RH. Incidence of venous thromboembolism and the impact on survival in breast cancer patients. J Clin Oncol 2007; 25: 70-6.

[46] Alcalay A, Wun T, Khatri V, et al. Venous thromboembolism in patients with colorectal cancer: incidence and effect on survival. J Clin Oncol 2006; 24: 1112-8.

[47] Piccirillo JF, Tierney RM, Costas I, Grove L, Spitznagel EL Jr. Prognostic importance of comorbidity in a hospital-based cancer registry. JAMA 2004; 291: 2441-7.

[48] Monreal M, Trujillo-Santos J. Screening for occult cancer in patients with acute venous thromboembolism. Curr Opin Pulm Med 2007; 13: 368-71.

[49] Khorana AA, Kuderer NM, Culakova E, Lyman GH, Francis CW. Development and validation of a predictive model for chemotherapy-associated thrombosis. Blood 2008; 111: 4902-7.

[50] Lyman GH, Khorana AA, Falanga A, et al. American Society of Clinical Oncology guideline: recommendations for venous thromboembolism prophylaxis and treatment in patients with cancer. $\mathbf{J}$ Clin Oncol 2007; 25: 5490-505.

[51] Büller HR, Agnelli G, Hull RD, Hyers TM, Prins MH, Raskob GE. Antithrombotic therapy for venous thromboembolic disease: the
Seventh ACCP Conference on Antithrombotic and Thrombolytic Therapy. Chest 2004; 126 (Suppl 3): 401S-28S.

[52] Lee AY. Treatment of venous thromboembolism in cancer patients. Thromb Res 2001; 102: V195-208.

[53] Murchison JT, Wylie L, Stockton DL. Excess risk of cancer in patients with primary venous thromboembolism: a national, population-based cohort study. Br J Cancer 2004; 91: 92-5.

[54] Hutten BA, Prins MH, Gent M, Ginsberg J, Tijssen JG, Büller HR. Incidence of recurrent thromboembolic and bleeding complications among patients with venous thromboembolism in relation to both malignancy and achieved international normalized ratio: a retrospective analysis. J Clin Oncol 2000; 18: 3078-83.

[55] Lee AY, Levine MN, Baker RI, et al. Low-molecular-weight heparin versus a coumarin for the prevention of recurrent venous thromboembolism in patients with cancer. N Engl J Med 2003; 349: 146-53.

[56] Lee A. VTE in patients with cancer--diagnosis, prevention, and treatment. Thromb Res 2008; 123 (Suppl 1): S50-4.

[57] Hirsh J, Warkentin TE, Raschke R, Granger C, Ohman EM, Dalen JE. Heparin and low-molecular-weight heparin: mechanisms of action, pharmacokinetics, dosing considerations, monitoring, efficacy, and safety. Chest 1998; 114 (5 Suppl): 489S-510S.

[58] McLeod RS, Geerts WH, Sniderman KW, et al. Subcutaneous heparin versus low-molecular-weight heparin as thromboprophylaxis in patients undergoing colorectal surgery: results of the canadian colorectal DVT prophylaxis trial: a randomized, double-blind trial. Ann Surg 2001; 233: 438-44.

[59] Cohen AT, Davidson BL, Gallus AS, et al. Efficacy and safety of fondaparinux for the prevention of venous thromboembolism in older acute medical patients: randomised placebo controlled trial. BMJ 2006; 332: 325-9.

[60] Alikhan R, Cohen AT, Combe S, et al. Prevention of venous thromboembolism in medical patients with enoxaparin: a subgroup analysis of the MEDENOX study. Blood Coagul Fibrinolysis 2003; 14: 341-6.

[61] Khorana AA. The NCCN Clinical Practice Guidelines on Venous Thromboembolic Disease: strategies for improving VTE prophylaxis in hospitalized cancer patients. Oncologist 2007; 12: 1361-70.

[62] Geerts WH, Pineo GF, Heit JA, et al. Prevention of venous thromboembolism: the Seventh ACCP Conference on Antithrombotic and Thrombolytic Therapy. Chest 2004; 126 (3 Suppl): 338S400S.

[63] Altinbas M, Coskun HS, Er O, et al. A randomized clinical trial of combination chemotherapy with and without low-molecular-weight heparin in small cell lung cancer. J Thromb Haemost 2004; 2: 1266-71.

This is an open access article licensed under the terms of the Creative Commons Attribution Non-Commercial License (http://creativecommons.org/licenses/ by-nc/3.0/) which permits unrestricted, non-commercial use, distribution and reproduction in any medium, provided the work is properly cited. 